\title{
A Strategy for Integrating Professional Skills Development into a Manufacturing Engineering Curriculum
}

\section{Dr. Derek M. Yip-Hoi, Western Washington University}

Dr. Yip-Hoi received his Ph.D. from the Department of Mechanical Engineering at the University of Michigan in 1997. Following his Ph.D. he worked for several years with the NSF Engineering Research Center for Reconfigurable Machining Systems also at the University of Michigan. His work involved supervision of sponsored research projects that focused on developing software applications to assist manufacturers design and plan operations on manufacturing systems that could be rapidly reconfigured to meet changes to a product's design or production volume. Sponsors of this work included Ford, GM and Chrysler. In 2003 he joined the faculty of the Mechanical Engineering Department at the University of British Columbia as junior chair of an NSERC sponsored research program in Virtual Machining. After 3 years at UBC, he moved to the Department of Engineering Technology at Western Washington University to focus on teaching. His teaching and scholarship interests lie in the areas of design, CAD/CAM, CAPP and CNC machining. Dr. Yip-Hoi is currently director of Western's Manufacturing Engineering Program.

\section{Dr. David Gill P.E., Western Washington University}

Dr. David Gill is an Associate Professor of Manufacturing Engineering at Western Washington University where he specializes in CAD/CAM and CNC. Current research interests include machining of aramid honeycomb and evaluation methods for 3D printing. Prior to coming to Western, Dr. Gill was Principal Member of the Technical Staff at Sandia National Laboratories in Albuquerque, NM. At Sandia, Dr. Gill spent 7 years as a research engineer in high precision meso-scale manufacturing processes and also in Laser Engineered Net Shaping (LENS), a fully functional metal additive process. Other work at Sandia included 5 years as Thermal Energy Storage Technical Leader in the Solar Thermal Technologies organization. Dr. Gill earned his Ph.D. from North Carolina State University studying high precision optical replication methodologies, his Master's Degree in Mechanical Engineering from Purdue University developing computer aided fixture planning methods, and a BSME from Texas Tech University. 


\title{
A Strategy for Integrating Workplace Skills Development into a Manufacturing Engineering Curriculum
}

\begin{abstract}
$\underline{\text { Abstract }}$
Workplace skills development are an important though often an indirect outcome of Engineering curriculums. These skills are critical to successful careers in job environments where graduates must increasingly navigate the challenges of adaptation to new technologies and the ability to work within teams containing a broad diversity of technical and personal backgrounds and goals. These skills include what is often referred to as the "Professional" or "soft skills" such as the ability to communicate effectively, an appreciation of an engineer's "duty of care" to society and a disposition towards self-learning. However, they also include many that are more technical in nature including the ability to visualize in $3 \mathrm{D}$, troubleshooting, quantifying and mitigating risk and connecting cause and effect. These are typically lumped together as skills that support problem solving abilities.

This paper presents a strategy being developed for emphasizing skills development within a Manufacturing Engineering curriculum. It recognizes that some of these lumped skills of a more technical nature can get overlooked or do not receive explicit recognition when they are being practiced. This can contribute to a lack of appreciation for these by students, who overwhelmed by the details of problem solving or applying a technology are unaware that this skill is being practiced. 29 skills have been identified, vetted by the program's Industrial Advisory Committee and grouped into areas of Problem Solving, Communication and Collaboration, Manage and Act Professionally and Practice Lifelong Learning. Students are introduced to this skill set through a mapping between them and course outcomes that is discussed at the beginning of a course of study. A survey is then used at the end of the course to gage how students felt the targeted skills were enhanced through course activities. This helps to engage students as partners in development of these skills and as this strategy is advanced, it provides valuable feedback to the program as to whether the skill set being used is the most appropriate. The impact on faculty as they shape course experiences to integrate in awareness of the use of these skills will also be discussed.
\end{abstract}




\section{$\underline{\text { Introduction }}$}

The question of "What is a Workplace Skill?" and how engineering curriculums are designed to develop these is one of great importance. The expectation by employers is that graduates will have acquired broad exposure and significant practice of these before entering the workforce. But there is always some fluidity in what is recognized to be the important skill set and to what extent should an engineering degree prepare a graduate in their practice. Developers of curriculums are challenged because of the continuing requirement to base these upon an engineering-science foundation while at the same time needing to integrate in technology driven advances particularly those due to the advent of Industry 4.0. This revolution has at its core the automation of information, be it authoring, retrieval and management, analysis or dissemination. In this new era of industrialization, it is even more imperative that engineering programs understand how their curriculums are leading to the appropriate skills development and how the outcomes of these efforts are being assessed.

The dictionary meaning of Skill refers to expertise or the "ability to do something well". A Workplace Skill would then be one that provides expertise for success at completing tasks relevant to an employee's the area of work. For engineers, this at its highest level can be described as technical problem solving. This has aptly focused engineering degree programs on developing Problem Solving Skills in their curricula. At the same time, it's been well recognized that engineers do not problem solve by themselves. This has led to a complimentary category of skills commonly referred to as the Professional or Soft Skills. These include developing expertise in communication, teamwork, ethical practice and lifelong learning. This category of skills is also strongly emphasized in engineering curricula.

Given these definitions, the requirements for accreditation of engineering programs as stipulated by ABET, help in shaping curriculum to produce engineers with the appropriate Workplace Skills. Within Criteria 3 [1], the new 1-7 learning outcomes (as did the old a-k outcomes) provide an umbrella coverage for programs to develop their curricula and assessment tools to integrate in skills development. In this regard, one finds that there is a strong and explicit mapping between the criteria's outcomes and the Professional Skills (3 - Communication, 4 - Ethical Practice, 5 Teamwork, 7 - Lifelong Learning). The mapping to workplace problem-solving skills as captured in outcomes 1 (Problem Solving Methodology), 2 (Design) and 6 (Experimentation and Analysis) is much less explicit and open to interpretation. There is wisdom to this approach. It recognizes the sufficiency and universality of the Professional Skills across all engineering disciplines but that there is a need to tailor problem-solving skills to the specific engineering discipline and the emphases of specific regional engineering and industrial practices that a given program's graduates may serve. In this context, the discipline is Manufacturing Engineering and the industrial emphasis is aerospace production.

One important requirement captured in ABET Student Learning Outcome 2 (SLO 2) is that problem-solving should at some point in an engineering program capture the complexities encountered in workplace practice. This is typically realized through the capstone senior project experience where students must deal with realistic constraints in arriving at a solution. The 
engineering-science approach to engineering education poses the challenge of trying to avoid relegating other problem-solving experiences encountered by students in their courses to addressing "story-book" type problems. For these, students take inputs to the problem for granted as being valid without question (they are given by the textbook or by the instructor). There is also a prescribed methodology that the course content lays out to follow. However, in workplace practice there are problem solving experiences that do not rise to the complexity of a design problem that "story-book" type problem solving skills do not serve well. For manufacturing engineers these include the ability to "trouble shoot" and "investigate cause and effect".

In the remainder of this paper, we discuss the development of a strategy to make Workplace Skills development more explicit within a Manufacturing Engineering program. A set of 29 skills have been identified for study. These have been grouped into the 4 areas of Problem Solving, Communication and Collaboration, Manage and Act Professionally and Practice Lifelong Learning.

\section{Perspectives on Professional Skills Development}

It is recognized that the Grinter Report [3] in 1955 was transformational in moving engineering education to a science-based curriculum. In many ways this deemphasized practical engineering workplace skills development in favor of graduating engineers with stronger analytical skills based on their ability to apply sound scientific principles. Though laudable and well intentioned, it became apparent in the 80's and 90's with the emergence of globalized economies that the pendulum had swung too far in this direction and that a correction was needed. ABET's Engineering Criteria 2000 [2] approved in 1996 and used until recently for accrediting engineering programs, sought to achieve this by balancing the need for outcomes related to engineering problem solving with outcomes that promoted the societal context for engineering. This has resulted in a strong emphasis on introducing and assessing the professional skills into curricula. There has been much pedagogical research since on professional skills development. Examples of these include studies of developing global competencies [4], communications skills development including those that promote cross-cultural collaborations [5], leadership skills [6], [7], teamwork [8], and developing ethical reasoning and practices [9].

The oft-cited work by Shuman et al. [10] is one of note as it lays out the unfolding of this new emphasis on professional skills development over the past two decades and a historical perspective on the shifts in emphasis starting with the Grinter Report. This work is also prophetic on a number of points regarding the evolution of workplace skills when written back in 2005. One is the impact of off shoring of manufacturing to countries with low wage options and the impact that would have on shaping the engineering workforce in developed countries. Today we see that playing out in the increased emphasis on automation throughout manufacturing and the need for engineers who can design, integrate, operate and improve automated systems. Cheaper hardware means that this trend is not limited to large manufacturers with deep pockets. The authors also refer to the evolving role of information technology. Again, this is playing out 
through the impacts of Industry 4.0. Industry is looking increasingly towards skills in information automation that starts with authoring content but extends to information management, retrieval, customization, analysis and dissemination. New areas of expertise in Data Analytics and Machine Learning have emerged as a result. Engineers, particularly those involved in manufacturing cannot afford to insulate themselves from the impact of the information revolution. They need to acquire skills that enable them to function effectively in this new era of technology.

These two threads of the recognition of the importance of the professional skills, and the emergence of new skill needs as a result of Industry 4.0 require a more holistic approach to identifying and developing workplace skills. To this end we highlight in the following sections a strategy that recognizes both professional and problem-solving workplace skills that are essential for success of a manufacturing engineer.

\section{Skills for Manufacturing Engineers}

The temptation is to bundle all engineers together when it comes to workplace skills development. However, each engineering discipline does place varying levels of expectations in the every-day application of these skills given the responsibilities of a practicing engineer. For a manufacturing engineer, it is important to note that these careers are often filled by mechanical engineers who transition through additional training upon hire. Many may have had limited exposure to manufacturing related experiences during their studies and so it should be expected that their skills upon graduation may not necessarily align well with the demands of this discipline. A Manufacturing Engineering degree on the other hand has a curriculum designed to tailor a graduate's skills appropriately.

A manufacturing engineer needs to be able to engage at any point in a product development cycle. They obviously need problem solving skills to assist in the design of products. But they must also bring to bear a vast reservoir of knowhow about how products can be feasibly and cost effectively manufactured and how this impacts the design and selection of tooling and equipment for fabrication and production. They are the critical link between design and manufacturing responsible for the design of processes and process planning. And they are responsible for production and quality control where trouble shooting of production problems, continuous improvement and management of operations is the order of the day. For any problem, a manufacturing engineer may be interacting with product designers, production floor operators, quality control technicians, part suppliers, tooling and equipment vendors, the customer and management. These collaborators are often dispersed geographically, typically globally. As such they must be adept at communication and teamwork.

With the coming of Industry 4.0, the responsibilities and the skills for success are evolving. The increased need for automation of operations and information for all manufacturers (not just the largest) is changing and impacting the emphasis of the skill set. The Internet-of-Things as it extends to the factory floor is presenting opportunities and challenges for manufacturing engineers to leverage this information through data analytics and machine learning to improve profitability for their businesses. The other side of the coin is increasing the value derived from 
the information and modeling generated during the design and planning phases before production is initiated. The fusion of these two spheres of activities where modeling, simulation and analysis is informed by information generated during production to make real-time decisions that can improve throughput and quality, is becoming a major goal for industry.

Given the changing industrial landscape being ushered in by Industry 4.0, it is our contention that it's even more imperative that a complete picture of workplace skills and not just the professional skills be in-place to help guide how a manufacturing engineering curriculum is developing these. As a first step, it's a question of recognizing where these skills are being practiced throughout the curriculum and trying to engage students in partnering with faculty in their growth. The next step is to add experiences where the practice of a skill is missing. Thirdly, the question of the level of competency that can be feasibly attained and how this is assessed within an undergraduate degree program needs be addressed. Depending on the skill, this may already be happening as part of course or program outcomes assessment. But as mentioned earlier, technical problem-solving skills that are currently lumped together need to be decoupled to facilitate easier engagement by students and instructors.

\section{Strategy for Use of Skills in MFGE Curriculum}

The strategy adopted has the following goals:

1. Each skill can be easily explained, motivates engagement in skills development and is relatable to specific experiences that a student will encounter in the curriculum.

2. A holistic and complete framework of workplace skills that recognizes both the technical problem solving and professional skills.

3. A suitable decoupling of problem-solving skills so that each is easily identifiable in workplace practice.

4. Though not necessarily stated as course outcomes these skills can at a minimum be shown to derive from them.

A set of these skills have been identified by faculty and vetted by the program's Industrial Advisor Committee. These are listed in Table 1. They are divided into 4 themes, Problem Solve, Communicate and Collaborate, Manage and Act Professionally and Practice Lifelong Learning. These skills are worded as simply as possible so that they can be easily explained to students. The rationale for this is to motivate students to engage as a partner in developing these skills as appropriate throughout their program of study (goal 3). We note that it is a requirement that course syllabi list student learning outcomes. In one sense, many of these are technically oriented and focus on assisting with the assessment of problem solving, design work and the ability to effectively utilize related technologies. An example of these for the program's Introduction to CAM and CNC class (MFGE 332) is shown in Table 2. Also shown in this table is a mapping to the relevant ABET SLOs (both the new 1-7 and Criteria 2000 a-k). These outcomes, particularly those for problem solving are much more abstract than course SLOs, leaving room for programs to determine how these are assessed across a curriculum. 


\section{Table 1. Skill Set for Manufacturing Engineers}

Skill Set for Manfuacturing Engineers

A practicing Manufacturing Engineer should have the ability to:

\begin{tabular}{|c|c|c|c|c|c|c|}
\hline \multicolumn{2}{|c|}{ 1. Problem Solve: } & 1 & 2 & 3 & 4 & 5 \\
\hline a & Visualize in 3D and think spatially & $\mathrm{x}$ & $\mathrm{x}$ & & & \\
\hline $\mathrm{b}$ & Abstract/Deconstruct a problem into solvable chunks & & & $\mathrm{x}$ & & \\
\hline c & Troubleshoot & $\mathrm{x}$ & $\mathrm{x}$ & $\mathrm{x}$ & $\mathrm{x}$ & \\
\hline $\mathrm{d}$ & Exercise engineering intuition & & $\mathrm{x}$ & $\mathrm{X}$ & $\mathrm{x}$ & \\
\hline $\mathrm{e}$ & Investigate cause and effect & & & $x$ & & \\
\hline $\mathrm{f}$ & Systematically follow prescribed procedures and protocols & $\mathrm{x}$ & $\mathrm{x}$ & $\mathrm{x}$ & & \\
\hline $\mathrm{g}$ & Identify, Interpret and specify realistic constraints & $\mathrm{x}$ & $\mathrm{x}$ & & & \\
\hline $\mathrm{h}$ & Innovate and think creatively & & & & & \\
\hline $\mathrm{i}$ & Work with precision & $\mathrm{x}$ & $\mathrm{x}$ & & & \\
\hline $\mathrm{j}$ & Incorporate uncertainty into decision making & & & & & \\
\hline
\end{tabular}

2. Communicate and Collaborate:

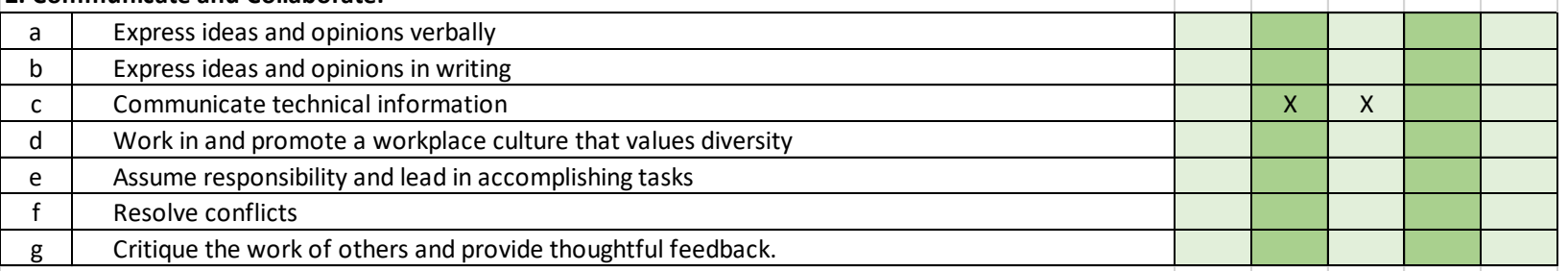

3. Manage and Act Professionally:

\begin{tabular}{|c|c|c|c|c|c|}
\hline a & Recognize and exercise a duty of care to society & & & & $\mathrm{x}$ \\
\hline $\mathrm{b}$ & Act with integrity & & & & $\mathrm{x}$ \\
\hline c & Practice effective time management & $\mathrm{x}$ & $\mathrm{x}$ & $\mathrm{x}$ & \\
\hline d & Plan activities, budget and manage resources & & & & \\
\hline $\mathrm{e}$ & Effectively utilize and manage technology & $\mathrm{x}$ & $\mathrm{x}$ & $\mathrm{x}$ & \\
\hline$f$ & Take and manage risk & & & & \\
\hline
\end{tabular}

4. Practice Lifelong Learning:

\begin{tabular}{|c|c|c|c|}
\hline a & Learn independently & & \\
\hline $\mathrm{b}$ & Receive, analyze and act on feedback & $\mathrm{x}$ & $\mathrm{x}$ \\
\hline c & Discover and interpret relevant information about a problem & & \\
\hline d & Discern the credibility of information & & \\
\hline $\mathrm{e}$ & Observe and adapt to changes & & \\
\hline \multirow[t]{3}{*}{$\mathrm{f}$} & Continuously improve in quality and efficiency & & $\mathrm{x}$ \\
\hline & MFGE 332 Course Outcome & & \\
\hline & Upon completion of the course, students will be able to: & & \\
\hline 1 & Generate programs for $\mathrm{CNC}$ machining using manual part programming techniques. & & \\
\hline 2 & Generate and verify programs for CNC machining using CAD/CAM and simulation software. & & \\
\hline 3 & \multicolumn{3}{|c|}{$\begin{array}{l}\text { Demonstrate knowledge of machining process planning, including cutting tool and parameter selection for operations } \\
\text { performed on a CNC machine. }\end{array}$} \\
\hline 4 & \multicolumn{3}{|c|}{$\begin{array}{l}\text { Demonstrate knowledge of the procedures to set-up, program, and operate CNC equipment to produce machined parts in } \\
\text { accordance with the specifications on a drawing. }\end{array}$} \\
\hline 5 & \multicolumn{3}{|l|}{ Apply knowledge of safety, health and environmental concerns in operating manufacturing equipment. } \\
\hline
\end{tabular}


Getting students motivated and engaged at these two levels is challenging. At the detailed course level, it can be difficult to get students to escape the trap of "losing sight of the forest for the trees." They appreciate what they are learning is of value but without a clear connection to a longer-term workplace skill development objective their efforts can devolve to "going through the motions". On the other hand, though it's helpful for students to appreciate the role of accreditation in maintaining curricula standards, the ABET SLOs (particularly the new 1-7) need significant parsing to make them relatable to student learning experiences. While this has been done by the faculty as illustrated by the mapping in Table 1, its value is often lost to the students.

The skill set presented in Table 2, offer a bridge to connect these two levels. Their simplicity and applicability to workplace practice makes them more relatable than the ABET SLOs. And as will be demonstrated in the next section, they can also be integrated into learning experiences within the courses to compliment the stated learning outcomes. This we argue helps to further motivate and engage students in those activities where at times the immediate and complete skills benefit might not be apparent.

Table 2. Student Learning Outcomes for MFGE 332 Introduction to CAM and CNC

Course SLO Students will be able to:

ABET SLO

\begin{tabular}{|c|l|c|}
\hline 1. & Generate programs for CNC machining using manual part programming techniques. & $\mathbf{1}(\mathbf{a}, \mathbf{k})$ \\
\hline 2. & $\begin{array}{l}\text { Generate and verify programs for CNC machining using CAD/CAM and simulation } \\
\text { software. }\end{array}$ & $\mathbf{1}(\mathbf{a}, \mathbf{k})$ \\
\hline 3. & $\begin{array}{l}\text { Demonstrate knowledge of machining process planning, including cutting tool and } \\
\text { parameter selection for operations performed on a CNC machine. }\end{array}$ & $\mathbf{2}(\mathbf{c})$ \\
\hline 4. & $\begin{array}{l}\text { Demonstrate knowledge of the procedures to set-up, program, and operate CNC } \\
\text { equipment to produce machined parts in accordance with the specifications on a } \\
\text { drawing. }\end{array}$ & $\mathbf{1 , 3}(\mathbf{k}, \mathbf{g})$ \\
\hline 5. & $\begin{array}{l}\text { Apply knowledge of safety, health and environmental concerns in operating } \\
\text { manufacturing equipment. }\end{array}$ & $\mathbf{4}(\mathbf{f})$ \\
\hline
\end{tabular}

\section{Industry Input to Skill Set Development}

As part of the process of developing this skill set, feedback was solicited from the program's Industrial Advisor Committee. This body comprises local and regional companies that hire graduates from the program. There was consensus that the skill set was accurate and complete in its coverage. Some of the comments received were:

1. A manufacturing engineering is a liaison between design and production. They need to be proficient in communicating in both spheres and often to non-engineers. This is particularly true when either providing or receiving feedback $(2 \mathrm{~g}, 4 \mathrm{~b})$.

2. Communication and collaboration skills are critical in particular communicating technical information to non-engineers (2.a-c). 
3. A critical skill is the ability to work through ambiguity ( $1 \mathrm{j}, 4 \mathrm{~d})$.

4. A manufacturing engineer must be able to deal with conflict (4f).

5. Skill is needed in identifying solutions to failures (1.c) and getting buy-in for the proposed solution (2a-c, e).

6. There must be comfort working on tasks with deliverables that are beyond one's control and an ability to manage completing work under these circumstances (1.j, 4.e).

7. Being able to assess, take and manage risk is critical. But also, the ability to communicate risk to others who maybe unfamiliar with them (3.f, 2.a-c).

8. Just showing up on time and staying off one's phone (2.b-c).

9. Avoid creating scrap (1.f, 1.i) but own up when it happens (2.e, 3.b).

\section{Examples of Use in MFGE Courses}

In this section we present some examples of how these skills are being developed within specific classes in a Manufacturing Engineering curriculum. To prime this experience for the students, a discussion of the skills and how they map to the course outcomes is included in a lecture early in the term. In this example we look at two courses MFGE 332 and MFGE 463 noting that the former is a prerequisite to the latter. In both, similar types of skills are practiced. Table 3 illustrates a mapping between skills and course outcomes.

\section{MFGE 332 Introduction to CAM and CNC}

- Visualize in 3D and Think Spatially (Skill 1.a)

3D Visualization is an important skill that is necessary for engineers and scientists. The impact of this skill on performance and ways to access and improve these has been well researched and documented [8]. Students taking MFGE 332 practice this skill in several ways. For machining process planning assignments and projects they must first visualize volumes of material corresponding to removal operations in the plan they develop. This requires them to decompose the total volume of material to be removed into machining features. They accomplish this utilizing the CATIA V5 Prismatic Machining workbench which provides a 3D display of the initial, in-process and final workpiece states to assist in visualizing their planning choices. For each operation planned, a sequence of tool paths must then be generated to remove the associated material. This requires visualization of a tool moving through space. Wireframe display of tool paths superimposed on a shaded 3D model must be correctly interpreted to ensure proper cutting conditions are maintained and efficiency in repositioning, approach and retract moves. Finally, verification results must be correctly interpreted to determine if there is any excess material left or design surfaces unintentionally gouged. Figure 1 shows examples of the type of visual inputs students must be able to process to correctly generate tool paths. 


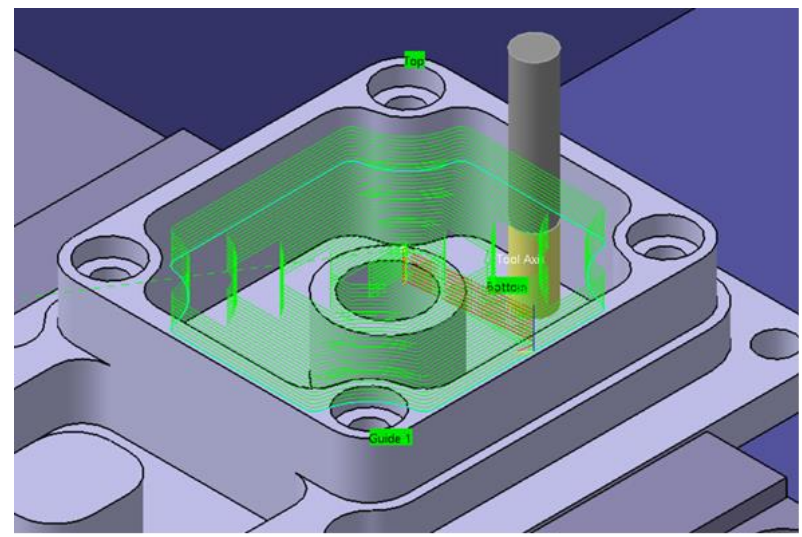

(a) Toolpaths for Machining a Pocket

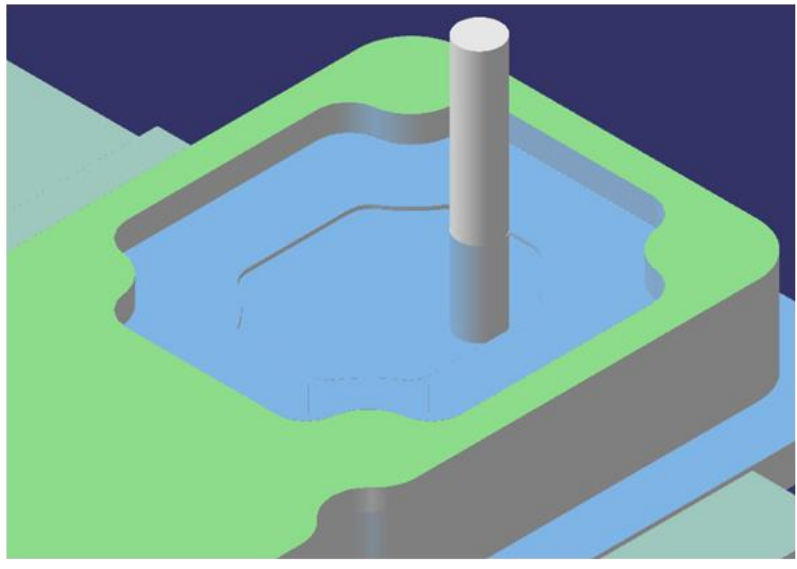

(c) Material Removal Simulation

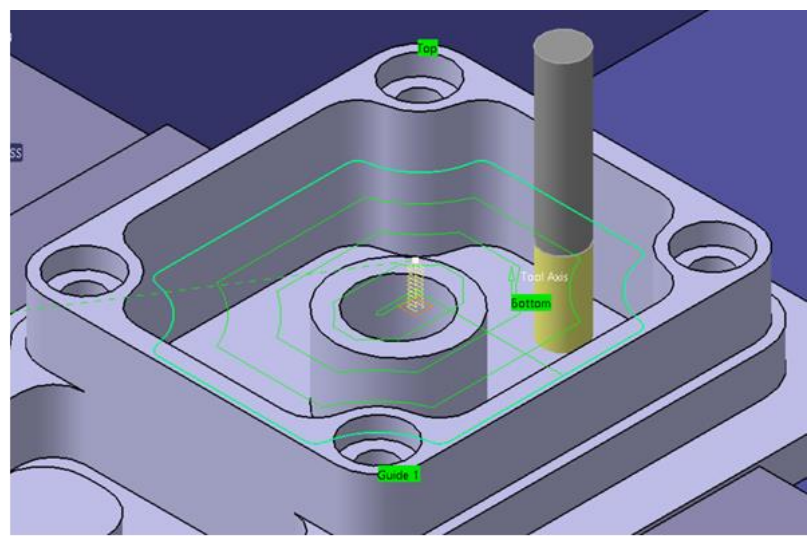

(b) Toolpaths for Machining one Level of a Pocket

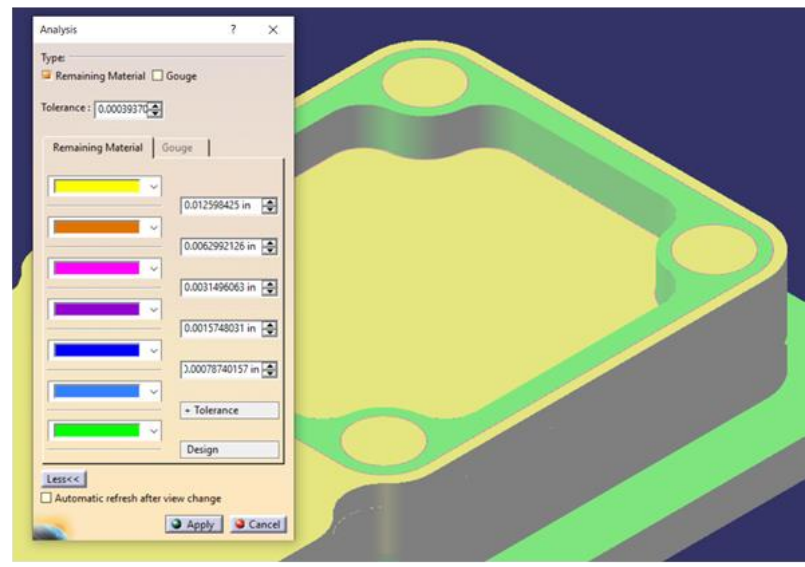

(c) Remaining Material

Figure 1. Examples of the types of Visualization Processing Needed for CAM Tool Path Planning

- $\quad$ Troubleshoot (Skill 1.c)

The dictionary definition of troubleshooting equates it with problem solving. While there is truth to this, it's important to make the distinction between classroom-type problem solving and workplace problem solving. Jonassen et al. [9] refer to the former as a "story (word) problem" where the parameters for the problem are defined in the problem statement. They further state that these types of problems have predetermined solutions that can be arrived at by following a prescribed set of rules or instructions. They argue that this leads to students developing a sense that problem solving is a procedure that can be memorized and habituated with an emphasis on arriving at answers rather than on extracting meaning. The trouble shooting emphasized in MFGE 332 is more typical of workplace problem solving which are more complex and ill-structed. It begins with validation of NC programs generated either manually or through use of the CATIA Prismatic Machining Workbench. Vericut is utilized to simulate and validate tool paths with errors being flagged either graphically or through logging. Typical errors include excess material and gouging (displayed graphically) or "fast feed rate" errors (logged). 
Troubleshooting requires a student to match the error to a poor decision made during tool path planning in CATIA. For example, a "fast feed rate" error might be due to an incorrectly set approach move that is insufficiently long enough to slow the tool from the rapid rate before entering the material resulting in a crash. This type of troubleshooting fits the illstructured problem-solving type that relies heavily on skill and experience based on workplace practice.

Students in MFGE 332 also experience troubleshooting during the set-up and operation of a $\mathrm{CNC}$ machine to execute their part program. Throughout a sequence of labs during the term and in a final capstone project they must execute procedures to assembly and load cutting tools, load and simulate programs on the controller and correctly establish work-offsets for the part to be machined. It is rare that a student runs a program without needing to troubleshoot a problem. For example, a heavy initial cut during a facing operation would indicate an incorrectly set tool length or work offset. Many of these problems can be identified and troubleshooted during the execution of the program. Others that are not immediately apparent manifest themselves in dimensional and surface finish variations in the final part. These provide the basis for students developing the skill of connecting cause and effect. This will be discussed in the next section

- $\quad$ Investigate Cause and Effect (Skill 1.e)

\section{- $y$ iltutoy/0}

\section{CERTIFICATE OF INSPECTION}

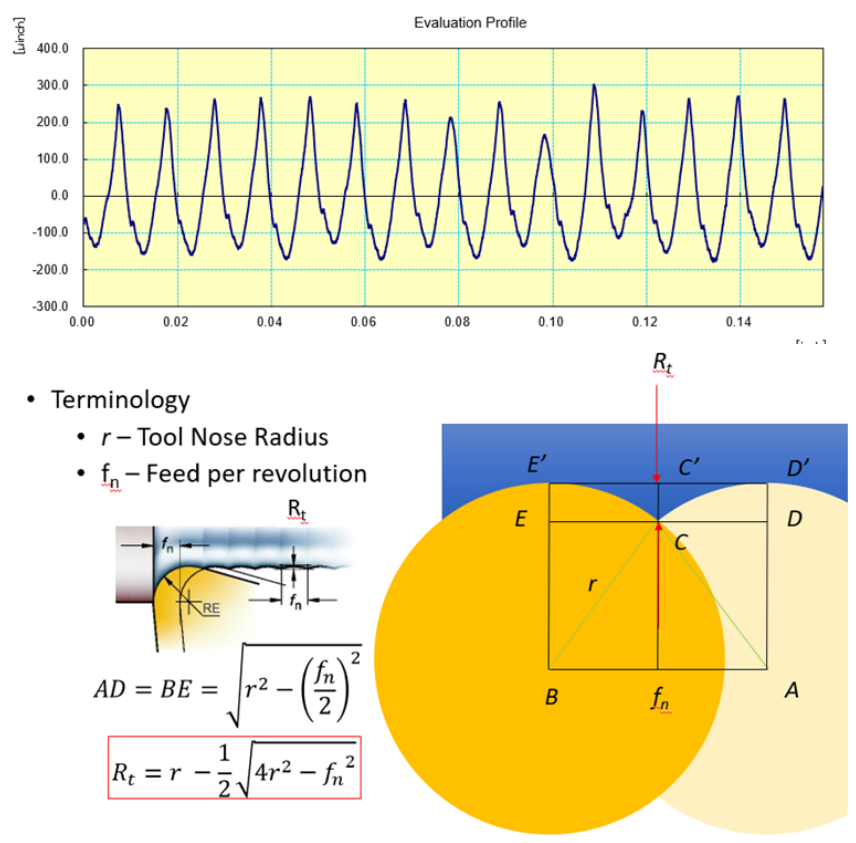

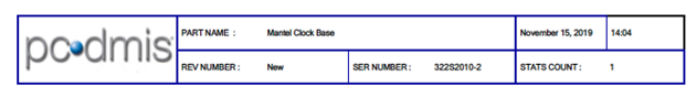

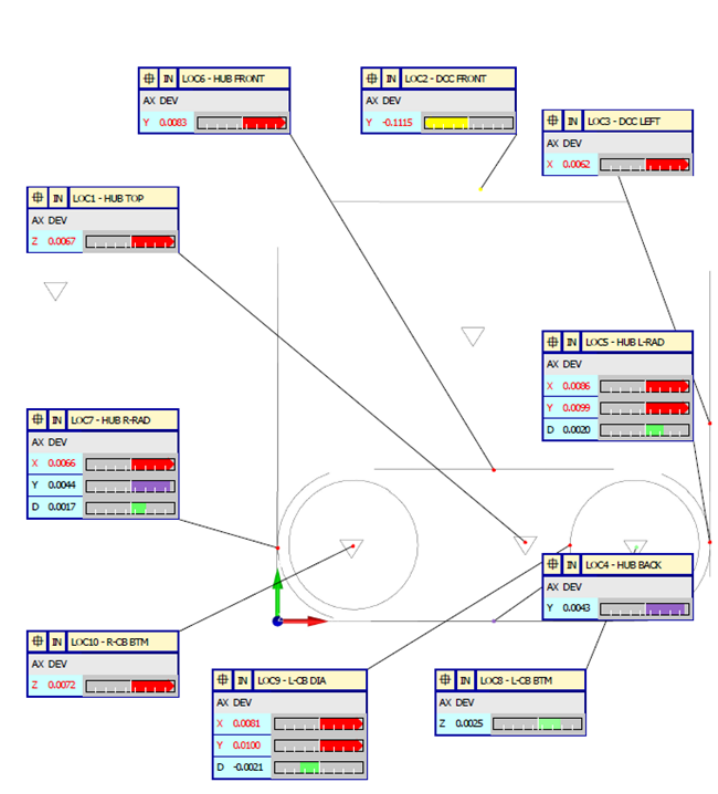

Figure 2. Example of Results Obtained from Surface Finish and CMM Measurements of CNC Machined Part. 
To practice this skill, students in MFGE 332 must take measurements off parts they have machined and visually identify any major defects from machining. A summary is then written that attempts to identify the courses for the effects observed. The measurements taken are key part dimensions using Brown and Sharp Coordinate Measuring Machines and surface finishes using Mitutoyo Profilometers. Figure 2 illustrates examples of the output generated from each. In the case of the former, the measured dimensions are compared to the nominal values with a \pm 0.005 " tolerance zone. Typical causes of variation identified by students include setup error as the workpiece is re-fixtured to have access from different directions and worn or incorrectly sized cutting tools. For finishes, the observed pattern, spacing and roughness value (peak-to-valley roughness, $R_{z}$ ) are correlated with theoretical values calculated using the cutter geometry and feed rate which can be selected by each student. Differences are explained by deflection and vibration.

The practice of this skill in MFGE 332 helps to raise awareness of the need to "close the loop" in manufacturing. This skill is refined in later classes on Quality Assurance and Design of Experiments where more systematic tools are introduced to assist students in investigating cause and effect.

\section{MFGE 463 Design of Tooling}

Gill and Newcomer [14] describe student-centered design activities called To the Boards that are practiced in this class to support simultaneous development of tooling design concepts at whiteboards around a classroom. These activities require the students to visualize complex fixturing challenges and to sketch solutions to the challenges that are then discussed with their teammates and later presented to the class. This happens in almost every class during a 10-week term (at least 16 out of 20 class meetings). Through these activities the students are practicing several of the skills listed in Table 1. These include 3D visualization (1.a), verbal presentation of ideas (2.a), identifying realistic constraints (1.g) and exercising engineering intuition (1.d). This class also devotes significant time to the discussion of determinism and constraint and the application of these ideas to a broad range of fixturing problems. This helps to develop a student's understanding of the importance of precision (1.i) and managing uncertainty (1.j) in arriving at solutions to these problems. Real life dictates that perfect determinism and constraint are appropriate choices for only a limited number of applications (e.g. high precision such as use of interferometers and similar instrumentation, diamond turning, semiconductor fabrication, etc.). Fixturing sufficiency for most other applications is best achieved by adding additional supports to a part which increases stability and load capability, simultaneously reducing determinism. Every fixturing condition requires that the student evaluate the level of uncertainty that is acceptable to an application and then to meet the other fixturing requirements without exceeding the acceptable uncertainty.

All this board work requires the students to express complex ideas verbally in front of their classmates and then to defend their ideas. In addition, several major projects require the students to complete a similar exercise in writing - they must evaluate their ideas and present justification for the design choices that were made. Both tasks are highly technical and work towards practicing the skill of communicating technical information (2.c). 
Having several group projects accounting for most of their grade, students must carefully manage their time (3.c). In addition, the quarter this class is taken has other demanding classes creating further demands. Because of this, the students must practice efficient time management, and many commented about the challenges experienced when projects were poorly managed and group work had to be completed at the last moment. Interestingly, the students did not see conflict resolution (2.f) as a skill practiced in this class even though every project had members with conflicting schedules and priorities that required adjustment for the good of the team. This might be partly explained by the students having the freedom to choose their teammates on all but the first project. The potential for conflict may have been reduced by self-selection accounting for the strengths and weaknesses of potential group members.

\section{Student Perception of Skills Development}

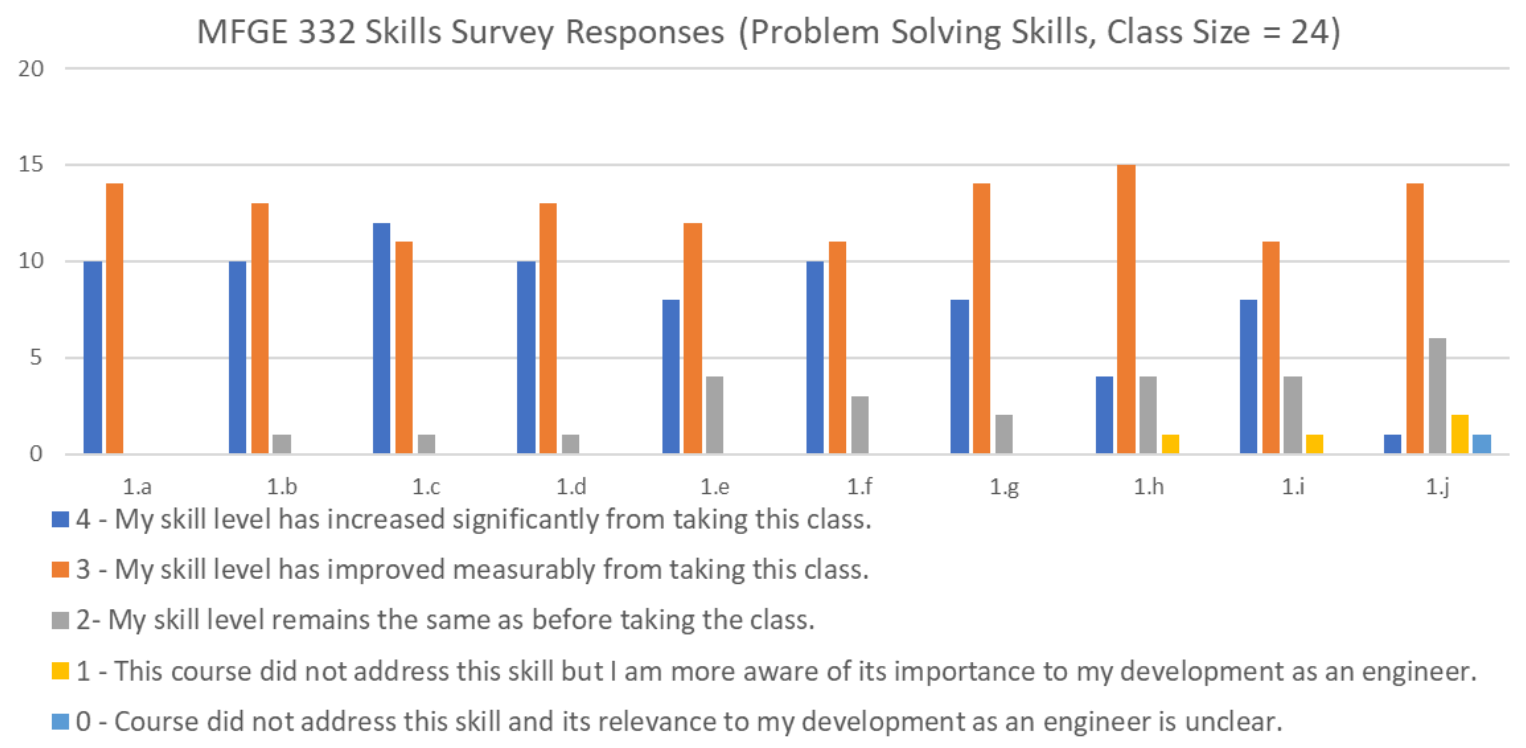

Figure 3. Skills Survey Responses for "Problem-Solving” Skills for MFGE 332

As part of the proposed strategy, students are surveyed upon completion of a course to determine their opinion on how their skills were impacted by their experiences. Figure 3 shows the responses for the problem-solving skills set from a recent offering of the MFGE 332 course described previously. The students surveyed were juniors in their second term taking courses required by the MFGE major. Not surprisingly, the vast majority of the class indicated improvement across all of the skills with 3D visualization (1.a) and trouble-shooting (1.b) receiving almost universal agreement (23 or 24 out of 24 ) and investigating cause and effect (1.e) only slightly behind (20 out of 24). We see that the class is less effective (though only marginally so) at developing skills to "Innovate and think creatively" (1.h), "Work with Precision" (1.i) and to "Incorporate Uncertainty into Decision Making" (1.j). Of these, to "Work with Precision" would be a skill to pay attention to as it is identified in Table 2 as one that MFGE 332 should develop. 


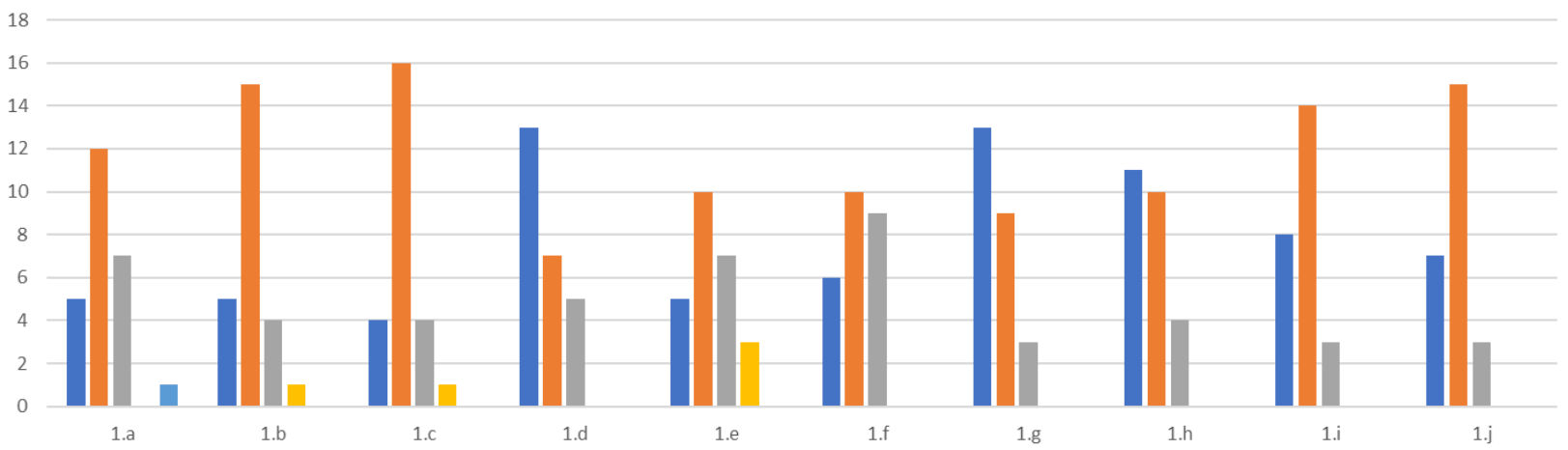

4 - My skill level has increased significantly from taking this class.

3 - My skill level has improved measurably from taking this class.

2- My skill level remains the same as before taking the class.

$\square 1$ - This course did not address this skill but I am more aware of its importance to my development as an engineer.

0 - Course did not address this skill and its relevance to my development as an engineer is unclear.

\section{Skill Set for Manfuacturing Engineers}

A practicing Manufacturing Engineer should have the ability to:

\section{Problem Solve:}

\begin{tabular}{|c|c|c|c|c|c|}
\hline \multicolumn{2}{|c|}{ 1. Problem Solve: } & \multirow{2}{*}{$\frac{1}{x}$} & \multirow[t]{2}{*}{2} & \multirow{2}{*}{$\frac{3}{x}$} & \multirow{2}{*}{$\frac{4}{x}$} \\
\hline $\mathrm{a}$ & Visualize in 3D and think spatially & & & & \\
\hline $\mathrm{b}$ & Abstract/Deconstruct a problem into solvable chunks & $\mathrm{x}$ & & & \\
\hline $\mathrm{c}$ & Troubleshoot & & & & $\mathrm{x}$ \\
\hline $\mathrm{d}$ & Exercise engineering intuition & $\mathrm{x}$ & & & $\mathrm{x}$ \\
\hline $\mathrm{e}$ & Investigate cause and effect & & & & \\
\hline $\mathrm{f}$ & Systematically follow prescribed procedures and protocols & $\mathrm{x}$ & & & $\mathrm{X}$ \\
\hline $\mathrm{g}$ & Identify, Interpret and specify realistic constraints & $\mathrm{x}$ & & $\mathrm{x}$ & $\mathrm{x}$ \\
\hline $\mathrm{h}$ & Innovate and think creatively & $\mathrm{x}$ & & $\mathrm{X}$ & $\mathrm{x}$ \\
\hline $\mathrm{i}$ & Work with precision & $\mathrm{x}$ & & $\mathrm{X}$ & $\mathrm{x}$ \\
\hline $\mathrm{j}$ & Incorporate uncertainty into decision making & $\mathrm{X}$ & & $\mathrm{x}$ & $\mathrm{X}$ \\
\hline & MFGE 463 Course Outcom & & & & \\
\hline & Upon completion of the course, students will be able to: & & & & \\
\hline 1 & \multicolumn{2}{|c|}{$\begin{array}{l}\text { Design tooling for different applications that may include jigs, inspection fixtures, workholding, presswork } \\
\text { dies, fixtures for joining, and thermoplastic molds. }\end{array}$} & & & \\
\hline 2 & \multicolumn{3}{|c|}{$\begin{array}{l}\text { Communicate tooling design and utilization through drawings, appropriate dimensioning and tolerancing, work } \\
\text { instructions, and written concept comparison, evaluation, and justification. }\end{array}$} & & \\
\hline 3 & \multicolumn{3}{|c|}{ Utilize design databases and standard parts during the design of tooling process. } & & \\
\hline 4 & \multicolumn{5}{|c|}{$\begin{array}{l}\text { Design tooling considering cost estimation, degrees of freedom, constraint, deformation, SMED principles, and applied loading } \\
\text { sources. }\end{array}$} \\
\hline
\end{tabular}

Figure 4. Skills Survey Responses for "Problem-Solving" Skills for MFGE 463 and Expected Mapping to Outcomes for Problem Solving

Figure 4. shows responses to the impact of MFGE 463 on developing problem-solving skills. This survey was conducted on almost the same cohort of students as the MFGE 332 survey. This was conducted in the first term of their senior year. Correlation between the student responses 
and the expected skills to outcomes mapping occurs for skills $1 . b$ through $1 . j$ with over $80 \%$ of the class indicating they saw some improvement save for the ability to "Investigate cause and effect" (1.e). For this, $40 \%$ indicated they saw no improvement, a result which is consistent with the absence of a mapping of this skill to any of the course outcomes. Less than $70 \%$ of the class saw improvement in 3D visualization skills (1.a). This lower than excepted result may be due to the association of 3D visualization skills to CAD training by the students. Though MFGE 463 requires use of CAD and the creation of drawings, this is purely the application of previously developed skills. Also of note in comparing the two surveys is the larger number willing to indicate that they saw no improvement in a particular skill as a senior over when they were a junior. Further study is needed to determine how much of this is reflective of the skills development in the classes versus students being more discerning in their responses after spending a year in the program.

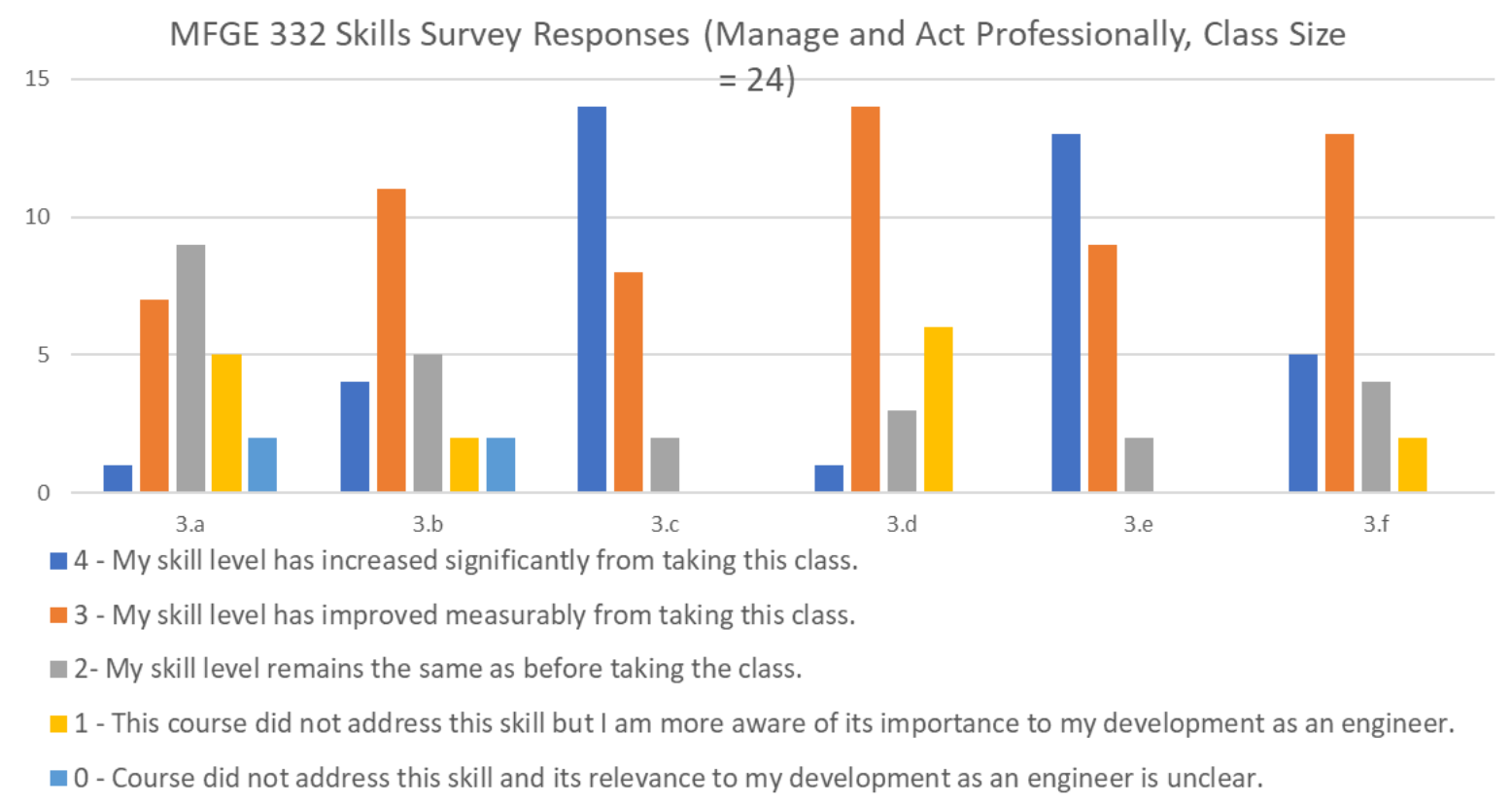

Figure 5. Skills Survey Responses for "Manage and Act Professionally" Skills in MFGE 332

The other skill categories show significantly more variability in the student responses. Again, this is not surprising since most of the skills practiced in these classes fall under the problemsolving group. However, even here there can be seen some agreement with the skills-tooutcomes mapping. For example, in MFGE 332 over $90 \%$ of the class (22 out of 24) agreed that their time management skills (3.c) and ability to effectively manage and use technology (3.e) improved (see Figure 5). However, the results from MFGE 463 are much less clear. Only $60 \%$ of the class felt that time management skills improved and less than $50 \%$ felt the class improved their ability to manage and utilize technology. Again of note is the significantly larger number of responses where seniors indicate no skill improvement. The maturing that occurs as juniors advance to seniors may well be a factor in these responses particularly in the perception of time management skills. Students are likely to have already adapted to the time management demands of being in an engineering program by the time they get to their senior year. On the ability to 
manage and utilize technology, students may have a different perception of the value of applying a previously developed skill to its improvement over the expectations of the program.

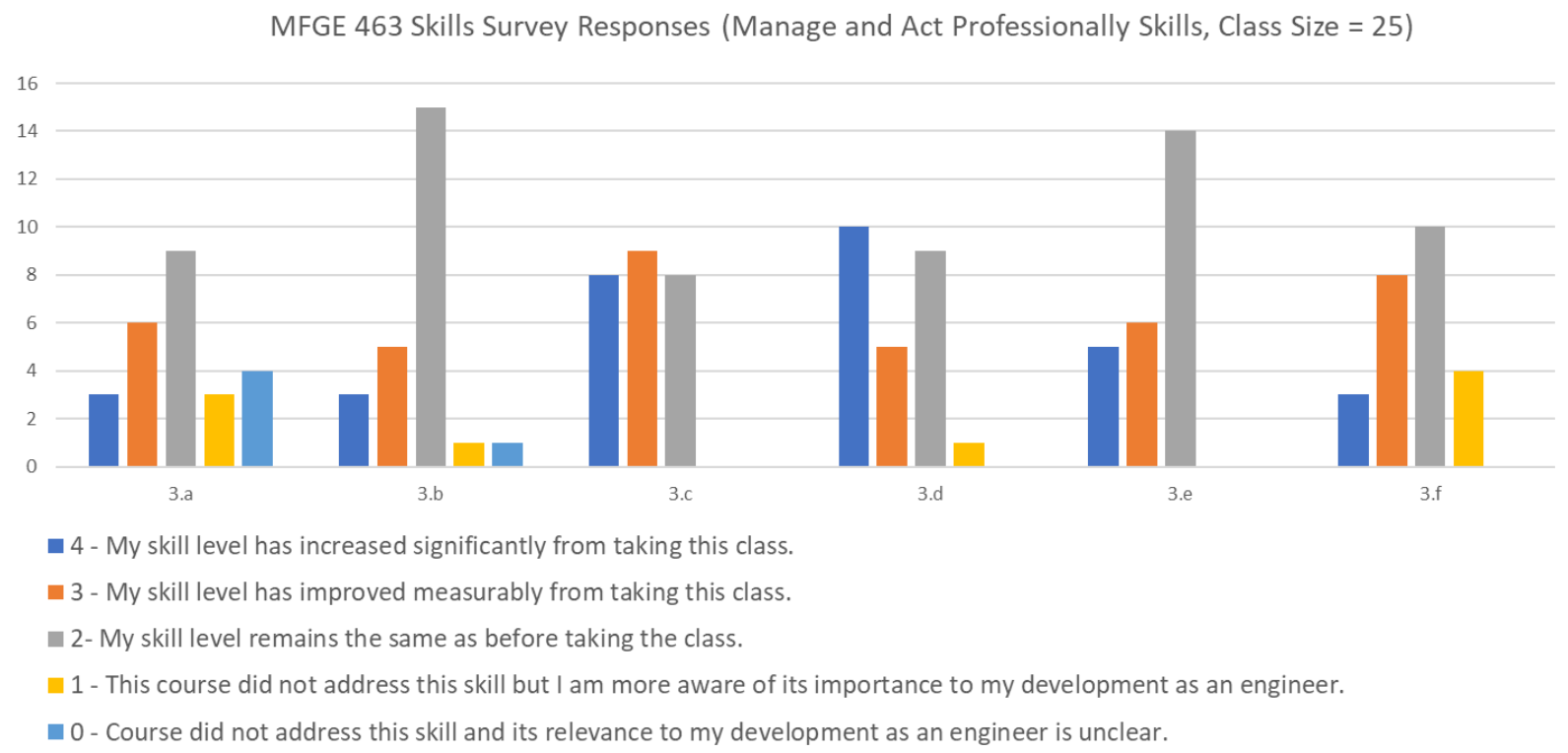

Figure 6. Skills Survey Responses for "Manage and Act Professionally" Skills in MFGE 463

\section{Future Plans}

The surveys described in the previous section will assist in determining if the program's vision of workplace skills development in courses throughout the curriculum align with the experiences of students. When significant disagreement occurs, this could mean a couple of things. First, the perception of the skill may differ significantly between program and student. This would necessitate further study of the skill as stated and how it is explained to students. Second, if there is agreement on understanding, the course content may not be doing enough in the students' opinions to develop the skill. This would require either improving experiences to develop that skill or reevaluating whether the course is the best place to promote development of that skill (i.e. change the mapping in Figure 1). The interpretation of the survey results also pose challenges. As discussed in the previous section, the maturity of students (senior versus junior) likely plays a role in how they evaluate their skills development. Additional data collected from new cohorts of students moving through the program would help in clarifying and accounting for these factors in interpreting the survey results.

As stated earlier the first goal of this strategy is to help motivate engagement of students in their workplace skills development. This happens alongside achieving course and ABET student learning outcomes. Of critical importance to realizing this goal is how students are introduced to these skills and their understanding of their meaning and application. As mentioned earlier, this introduction occurs as part of a lecture during the first weeks of a course in which a skills survey is conducted. We believe this would be better delivered as part of a student's pre-major experience before admission to the MFGE program, allowing for a more contextual explanation 
of the relevant skills at the start of each course that is focused on those most critically impacted by the course context. This is particularly important for the problem-solving skills. Even with the effort to simplify these, perception of these can vary if they are not clearly defined. Providing specific examples of how the skills will be practiced during the term as part of the course introduction would help to improve understanding of their meaning leading to more discernment in the responses provided in the survey.

The question of completeness and desired level-of-detail of the proposed skill set is also one that needs further consideration. As an example, the skill to "Effectively Utilize and Manage Technology" can mean many things depending on the context and is so open to interpretation. In MFGE 332 students utilize both software (e.g. CAD/CAM) and hardware (CNC) technologies in their assignments and labs. In their assessment of this skill when surveyed, they are lumping these experiences together. At the same time, the goals of training manufacturing engineers in $\mathrm{CAD} / \mathrm{CAM}$ and $\mathrm{CNC}$ are somewhat different. The expectation that an engineer would be operating a CNC machine upon graduation is low, while on the other hand they could well be doing significant CAD/CAM work as a designer or part-programmer. In fact, exposure to CNC operations has as much an impact on other skills development (e.g. 1.c-e) as it does on the ability to utilize and manage technology. There is also the question of more generic, critical technology skills that can be overlooked by grouping into this one skill. For example, just the skill at using a computer is often assumed but often varies significantly from student to student. ABET's Criteria 2000 Criteria 3 provided a learning outcome that programs could use to specifically assess the ability of students to utilize technologies appropriate to engineering practice (outcome k). Though less explicit in the new criteria, this will continue to be measured using specific course outcomes. This maybe one case where workplace skill development is better measured using specific course outcomes rather than the single proposed skill.

\section{Conclusion}

This paper has presented a strategy being developed to integrate consideration of a complete set of workplace skills into a manufacturing engineering curriculum. In addition to the professional or soft skills, 11 problem-solving skills have been identified including the ability to "Visualize in 3D and think spatially", "Troubleshoot" and "Exercise Engineering Intuition". One of the goals to creating these is to use them to motivate engagement by students in their skills development. Vetting on the part of the program's Industrial Advisory Committee showed strong agreement with the proposed skill set. Examples of how these skills are being practiced in two required courses in the program have been presented and surveys of students on their perception of their development have been collected. These show in most cases a correlation with the program's expectations. Future plans will lead to improved explanations with contextual examples of these skills and introduce them to students earlier in their studies when they are pre-majors. Survey results will be used to identify if the skill set needs to be adapted or aligned with the curriculum in a different way. 


\section{$\underline{\text { References }}$}

1. ABET, "Criteria for Accrediting Engineering Programs, 2019 - 2020", $1^{\text {st }}$ February, 2020, https://www.abet.org/accreditation/accreditation-criteria/criteria-for-accrediting-engineeringprograms-2019-2020/.

2. ABET, "Criteria for Accrediting Engineering Programs, 2016 - 2017", $1^{\text {st }}$ February, 2020, https://www.abet.org/accreditation/accreditation-criteria/criteria-for-accrediting-engineeringprograms-2019-2020/. https://www.abet.org/accreditation/accreditation-criteria/criteria-foraccrediting-engineering-programs-2016-2017/\#GC3

3. Grinter Report, published in the Journal of Engineering Education, Vol. 83, No. 1, 1994, pp. $74-93$.

4. Lohmann, J.R., Rollins, H.A. and Joseph Hoey, J., 2006. Defining, developing and assessing global competence in engineers. European journal of engineering education, 31(1), pp.119131.

5. Gilleard, J. and Gilleard, J.D., 2002. Developing cross-cultural communication skills. Journal of professional issues in engineering education and practice, 128(4), pp.187-200.

6. Farr, J.V. and Brazil, D.M., 2009. Leadership skills development for engineers. Engineering Management Journal, 21(1), pp.3-8.

7. Kumar, S. and Hsiao, J.K., 2007. Engineers learn "soft skills the hard way": Planting a seed of leadership in engineering classes. Leadership and management in engineering, 7(1), pp.1823.

8. Lingard, R.W., 2010. Teaching and assessing teamwork skills in engineering and computer science. Journal of Systemics, Cybernetics and Informatics, 18(1), pp.34-37.

9. Colby, A. and Sullivan, W.M., 2008. Ethics teaching in undergraduate engineering education. Journal of Engineering Education, 97(3), pp.327-338.

10. Shuman, L.J., Besterfield-Sacre, M. and McGourty, J., 2005. The ABET "professional skills"-Can they be taught? Can they be assessed?. Journal of engineering education, 94(1), pp.41-55.

11. Siller, T.J., Rosales, A., Haines, J. and Benally, A., 2009. Development of undergraduate students' professional skills. Journal of Professional Issues in Engineering Education and Practice, 135(3), pp.102-108.

12. Sorby, S.A., 2009. Educational research in developing 3-D spatial skills for engineering students. International Journal of Science Education, 31(3), pp.459-480.

13. Jonassen, D., Strobel, J. and Lee, C.B., 2006. Everyday problem solving in engineering: Lessons for engineering educators. Journal of engineering education, 95(2), pp.139-151.

14. Gill, D.D. and Newcomer, J.L., 2017, November. "To the Boards": Team-Based Design for Student-Centered Learning. In ASME 2017 International Mechanical Engineering Congress and Exposition. American Society of Mechanical Engineers Digital Collection. 